\title{
Immunoregulatory properties of clinical grade mesenchymal stromal cells: evidence, uncertainties, and clinical application
}

\author{
Cédric Ménard ${ }^{1,2,3}$ and Karin Tarte ${ }^{1,2,3^{*}}$
}

\begin{abstract}
Mesenchymal stromal cell (MSC)-based therapy holds great promise for treating immune disorders and for regenerative medicine in agreement with their paracrine trophic and immunosuppressive activities. Various processes have been developed worldwide to produce clinical grade MSCs but, so far, it is not known if one given MSC is more efficient than another. In addition, while their broad activity on innate and adaptative immune cell subsets is now widely admitted, the precise mechanisms supporting their immunoregulatory capacities are still a matter of debate. Finally, quantitative immunological potency assays correlated to clinical efficacy and clinically relevant immunomonitoring approaches for MSC-treated patients are sorely needed. Multiple parameters could influence the immunomodulatory potential of therapeutic MSCs. The most important challenge is now to differentiate, within a high number of poorly comparable and even contradictory pre-clinical studies, the parameters that could have some clinical impact from those that are only due to uncontrolled experimental variability. Importantly, besides MSC-related differences, primarily linked to production processes, several important variables associated with immune assays themselves, including selection of effector immune cells, activation signals, and read-out techniques, should be carefully considered to obtain solid results with potential therapeutic application. In this review, we establish a core of common and reproducible immunological properties of MSCs, shed light on technical issues concerning immunomodulatory potential assessment, and put them into perspective when considering clinical application.
\end{abstract}

\section{Introduction}

Interest in adult mesenchymal stromal cells (MSC) as a promising tool in regenerative medicine and for treating severe immune-mediated diseases has increased over the past decade [1]. Whereas human tissue-resident MSCs are poorly characterized, the possibility to expand ex vivo high numbers of clinical-grade MSCs has paved the way for their therapeutic use. In agreement, more than 250 clinical trials evaluating MSC therapy have been registered and preliminary encouraging results - which should now be confirmed in large randomized phase II/III trials - have been recently reported in graft-versus-host-disease, fistulating Crohn's disease, progressive multiple sclerosis, kidney transplant

\footnotetext{
* Correspondence: karin.tarte@univ-rennes1.fr

${ }^{1}$ SITI Laboratory, Etablissement Français du Sang Bretagne, CHU Rennes,

Rennes F-35043, France

${ }^{2}$ INSERM U917 - Faculté de médecine, 2 Avenue du Pr Léon Bernard, Rennes 35043, France

Full list of author information is available at the end of the article
}

rejection, and ischemic cardiomyopathy [2-6]. The increasing use of MSCs has led to the development of large-scale production processes according to good manufacturing practice (GMP) requiring a strict monitoring of all critical aspects classically associated with cell therapy products [7]. In addition, expansion of clinical-grade MSCs involves specific parameters, in particular tissue sources and culture conditions. Besides the poorly acknowledged influence of donor-related variability, MSCs can be readily obtained from either bone marrow or adipose tissue and some discrepancies have already been reported in phenotypic, proteomic, transcriptomic, and differentiation profiles between bone marrow-derived MSCs (BM-MSCs) and adipose-derived MSCs (ADSCs) [8-10]. In addition, no consensus has emerged on the best MSC culture conditions, including: starting from unfractionated cells versus cells selected by density-gradient separation or by cell-sorting based on specific surface markers; use of fetal calf serum 
versus human platelet lysate; cell seeding density; and number of population doubling that accurately reflects the scale of cell expansion and determines culture-related senescence. The potential impact of these parameters on product fitness and function remains a matter of debate.

It is now widely accepted that the clinical potential of MSCs essentially relies on their short-term paracrine ability to reduce inflammation, inhibit immune responses, and produce trophic factors. Any variability in the MSC production process could contribute to a modulation of their immune properties. In addition, the great diversity of experimental protocols used to monitor MSC immune properties favors result inconstancy, thus blurring global interpretation of the data [11]. Importantly, besides the general concerns about the validity of mouse models, major interspecies differences amongst the molecular pathways supporting immunoregulatory activity of murine versus human MSCs have been reported [12], making it crucial to design fully validated in vitro immunological assays. Such coordinated efforts would be helpful to better understand the mechanism of action of GMP-grade MSCs and optimize their further clinical use.

\section{Immunoregulatory properties of mesenchymal stromal cells: common features}

MSCs exert their immunoregulatory effects on a large panel of effector cells of adaptive and innate immunity, including $\mathrm{T}$ cells, B cells, natural killer cells, monocytes/ macrophages, dendritic cells and neutrophils $[1,13]$. They have been shown to arrest activated T cells in the G0/G1 phase of the cell cycle and to decrease their production of IFN- $\gamma$ and IL-2, to downregulate cytotoxic T lymphocyte-mediated cytotoxicity, to favor the growth of natural regulatory $\mathrm{T}$ cells, and to drive $\mathrm{CD} 4^{\text {pos }} \mathrm{T}$ cells, including fully differentiated Th17, into regulatory phenotype and function. Similarly, MSCs alter the proliferation, cytotoxicity, and IFN- $\gamma$ production of natural killer (NK) cells, and $\gamma \delta$ T cells $[14,15]$. Furthermore, they interfere with the differentiation of dendritic cells, and impair their maturation into fully functional antigen-presenting cells [16]. Similarly, MSCs promote a macrophage reprogramming towards an IL- $10^{\text {pos }} \mathrm{TNF}$ $\alpha^{\text {neg }}$ M2-like phenotype, associated with tissue repair and tumor progression [17-19].

Importantly, inhibition of immune cells relies essentially on a combination of soluble factors that are not constitutively expressed by MSCs but are induced following MSC priming by inflammatory stimuli [20]. Conversely, resting MSCs have supportive and antiapoptotic activities towards various cell types, including T cells, B cells, NK cells and neutrophils [21-23]. As a consequence, resting MSCs favor the survival and proliferation of highly purified activated B cells, which do not produce IFN- $\gamma$, whereas previous treatment of MSCs with exogenous IFN- $\gamma$ converts them into a B-cell inhibitory phenotype [23]. The net effect of MSCs on Bcell differentiation remains unclear [24]. In addition, MSCs could behave as antigen-presenting cells in some specific contexts, a property that could favor immune rejection and low persistence in vivo [25]. IFN- $\gamma$ plays a pivotal role, in collaboration with TNF- $\alpha$ and IL- $1 \alpha / \beta$,in the triggering of the inhibitory machinery of MSCs [20]. MSCs display a wide range of inhibitory mechanisms that are essentially redundant in their pathways of induction and functional consequences. Among them, the tryptophan-catabolizing enzyme indoleamine 2,3dioxygenase (IDO) appears as the most robust T-cell and B-cell inhibitory system induced by IFN- $\gamma$ in human MSCs, whereas mouse MSCs preferentially use inducible nitric oxide synthase [12]. Similarly, IL-10-dependent production of soluble HLA-G5 molecule by human MSCs was involved in the expansion of regulatory $\mathrm{T}$ cells [26], whereas no murine homologue of HLA-G has been identified. Among the most reproducibly reported immunoregulatory pathways activated in primed human MSCs, one should also highlight prostaglandin-E2, which is supposed to play a pivotal role in NK inhibition [14], and TNF- $\alpha$-induced protein 6 (TSG-6), which influences neutrophil extravasation directly and through the inhibition of Toll-like receptor (TLR)-dependent activation of resident macrophages [27,28]. Interestingly, TSG-6 is the only MSC-derived factor described so far as sufficient per se to reproduce the therapeutic activity of MSCs in several animal models of cardiac, lung, and cornea injury [28-30]. Finally, it should be noted that a common property of human and mouse MSCs is their capacity to produce, in particular after stimulation by IFN$\gamma$ and TNF- $\alpha$, high levels of inflammatory chemokines that may recruit immune cells into close proximity with inhibitory MSCs $[31,32]$.

\section{Immunoregulatory properties of mesenchymal stromal cells: experimental pitfalls}

Although the headlines of MSC immunoregulatory properties are quite well defined, the wide heterogeneity of in vitro experimental settings has generated disparate and poorly comparable results, thus limiting both the general interest and the clinical impact of these studies. In addition, lack of standardization could lead to a loss of insightful information embedded in uncontrolled technical variability. Two main variables could apply to the conundrum at hand: MSC-related parameters and immune cell-related parameters (Figure 1).

Considering MSC-related parameters, we already underlined that studies dealing with murine MSCs could essentially not be directly transposed to human MSCs. In addition, we and others have recently demonstrated 


\section{MSC-related parameters}

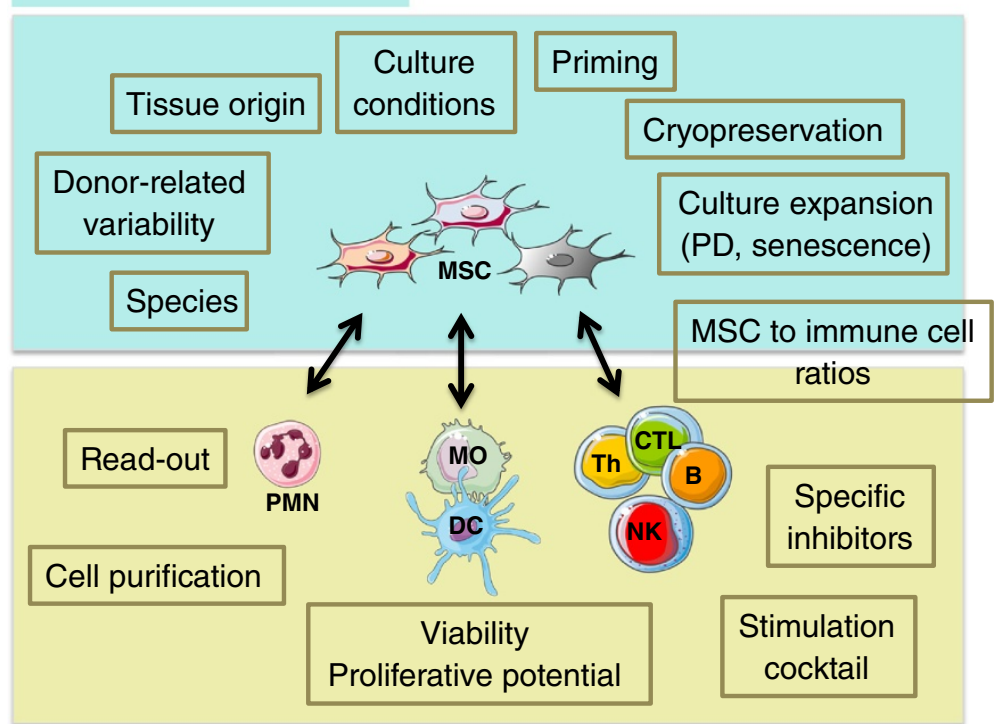

Immune cell-related parameters

Figure 1 Critical parameters for assessment of mesenchymal stromal cell immunomodulatory potential. Multiple factors could impact the study of mesenchymal stromal cell (MSC) immunomodulatory capacities, including MSC-based and immune cell-based variables. Standardization of these parameters is of utmost importance to ensure reproducibility of the experiments. B, B cells; CTL, cytotoxic T lymphocytes; DC, dendritic cells; MO, monocytes/macrophages; NK, natural killer cells; PD, population doubling; PMN, polymorphonuclear neutrophils; Th, T helper cells.

that human MSC source and culture conditions could modulate their capacity to inhibit immune response [33], indicating that a careful description of all culture parameters, as required for GMP-grade production, is mandatory to interpret immunological data. Of note, large studies comparing ADSCs and BM-MSCs obtained from the same donors using identical procedures are still lacking so no definitive conclusions can be made on the direct impact of cell sources on MSC properties. A major concern remains inter-individual variability, since phenotypically indistinguishable MSCs produced from healthy donors could display strongly different capacities to produce cytokines and respond to inflammatory licensing $[18,34]$. As recently stated by the International Society for Cellular Therapy (ISCT) MSC committee, GMP-grade MSC immune properties should be validated using both resting and primed cells, in agreement with their use in local or systemic inflammatory clinical settings [11]. Whatever the selected licensing stimulus, its composition and kinetic should be carefully standardized. A combination of IFN- $\gamma$ and TNF- $\alpha$ for 40 hours has been proposed as the standard MSC licensing protocol but TLR ligands are also well known to variably modify MSC immune properties and should be considered depending on the specific clinical application [20].
Another crucial parameter is the cell culture expansion evaluated by the cumulative number of population doubling. Large-scale expansion could be theoretically associated with genetic instability, even if human MSCs, unlike murine MSCs, do not transform in vitro $[11,35]$. Moreover, it could also give rise to loss of differentiation potential, clonal selection, and replicative senescence, a process that could modulate immune properties [36,37]. In particular, senescence-associated secretory phenotype is characterized by the release of numerous inflammatory cytokines, chemokines, and growth factors [38]. Interestingly, whereas the MSC dose did not affect response rate in patients treated for steroid-resistant graftversus-host disease, infusion of early passage MSCs was correlated to both better response and better survival when compared with late passage MSCs [39]. The functional consequences of senescence-related modifications on MSC immunoregulatory potential remain to be fully elucidated. The impact of donor-related variability and replicative senescence is probably even more preeminent when considering industry-sponsored MSC trials in which a single donor sample is used to produce large lots of numerous cell doses (universal donor approach), whereas academic-driven trials use minimally expanded MSCs (one donor/one recipient approach) 
[40]. Importantly, the number of passages is a poorly reliable parameter to evaluate MSC lifespan, and determination of cumulative population doubling should be systematically recorded as a standardized cell qualification control.

Finally, an underestimated source of variability is the cryopreservation of MSCs. Almost all clinical trials use cryopreserved MSCs immediately after thawing. Recent studies suggest that MSCs thawed for less than 24 hours display reduced immune suppressive properties in vitro [41]. Immunological assays should thus clearly specify whether MSCs are cryopreserved products or not and whether a post-thawing 'rescue' phase has been used.

When focusing on immune cell-related parameters, a precise description of the most important variables is also required, including strict qualification of effector immune cells, use of various MSC to immune cell ratios, definition of reproducible immune cell activation signals, and use of fully validated read-out techniques, including appropriate internal controls [11,33]. First, the use of negatively selected highly purified immune cell subsets instead of whole peripheral blood mononuclear cells should be favored to avoid confounding effects of thirdparty cells on both immune cell and MSC activation status. In order to increase result reproducibility, in particular when comparing GMP-grade MSC batches in quantitative assays, the use of cryopreserved batches of functionally validated T, B, and NK cells, or monocytes is helpful to reduce technical variability. Particular attention should be paid to the purification of peripheral blood neutrophils since the time between blood harvesting and cell processing, the purification procedure, as well as the presence of minute amounts of endotoxin could significantly alter their functions. Importantly, high viability and high proliferative capacity of $\mathrm{T}, \mathrm{B}$, and $\mathrm{NK}$ cells are required to avoid interference with the antiapoptotic activity of MSCs and subtle alterations of these parameters can profoundly affect the biological conclusions. In this respect, as various stimuli have been used to activate immune cells, including mitogens, cytokines, polyclonal activation of antigen receptor, and specific antigens, an important recommendation is to set up the best parameters for optimal cell activation and minimal cell death (culture medium, duration of the stimulation, composition of the stimulatory cocktail). Importantly, whereas B-cell receptor or $\mathrm{T}$-cell receptor triggering is completely B-cell or T-cell specific, several stimuli regularly used to activate immune cells trigger simultaneous activation of MSCs, leading to a more complex interpretation of the results. This is particularly the case for TLR3 and TLR4 ligands, which are convenient activators of myeloid cells but can also act on MSCs. Finally, a detailed description of the read-out techniques and interpretation is also mandatory. To date, no phenotypic marker has been reliably demonstrated as predictive for MSC immunoregulatory potential. In agreement, a recent working proposal of the ISCT MSC committee reviews the most frequently used functional in vitro assays to evaluate the interplay between MSCs and various immune cell subsets [11].

Among the various mechanisms involved in the immunosuppressive activity of human MSCs, IDO plays a pivotal role in both inhibition of T-cell and B-cell proliferation and induction of IL-10-producing M2 macrophages [18]. IDO can be evaluated at several levels: RNA by quantitative PCR; protein by western blot or immunofluorescence; activity by quantification of tryptophan and kynurenin in culture supernatant; and function by the use of its highly specific chemical inhibitor, the L-1 methyltryptophan. In keeping with the multiple levels of regulation of IDO, we found no link between IDO mRNA level and T-cell inhibition but a good correlation exists between the capacity of MSCs to suppress T cells and to express IDO protein and enzymatic activity after inflammatory licensing [18,33]. Since quantification of IDO catalytic activity in response to increasing dose of IFN- $\gamma$ is easy to standardize, it could be useful as a quantitative qualification control for selection of MSC donors, or GMP culture processes. Of course, other inhibitory pathways could be also explored, using specific chemical inhibitors and/or small interfering RNA strategies.

\section{Immunoregulatory properties of mesenchymal stromal cells: unsolved questions}

Whereas an increasing number of recently published papers have focused on the inhibition of immune responses by MSCs, few have developed strategies to understand how immune cells modify MSC properties in turn. Besides the well-recognized licensing role of immune cell-derived IFN- $\gamma$, several other soluble and membrane factors could have a direct impact on MSC immune plasticity. As an example, B/T cell-derived lymphotoxin is involved in the differentiation of ADSCs into lymphoid stromal cells that regulate immune cell homing and activation within secondary lymphoid organs through expression of chemokines, cytokines, and adhesion molecules [42]. Similarly, CD40L activates NF- $\mathrm{kB}$ signaling in MSCs and triggers expression of inflammatory cytokines whereas IL-4 strongly induces the expression of CD106 (our unpublished data). It is tempting to speculate that, as described for tumor cell/ stromal cell crosstalk, the contact with variably activated immune cells in vivo could drive MSC immune polarization.

Such mechanisms are currently under evaluation in vitro but the physiological role of native MSCs as immunosuppressive cells and their capacity to receive 
immune cell-derived signals remain questionable. The recent demonstration that hematopoietic stem cell niche should be considered as a localized immune-privileged site maintained by regulatory $\mathrm{T}$ cells raises the question of the role of MSCs in this process [43]. Conversely, perivascular BM-MSCs could sense circulating TLR ligands and, by producing CCL2, modulate the frequency of bloodstream inflammatory CCR2 ${ }^{\text {pos }}$ monocytes, thus enhancing antimicrobial defense but also potentially exacerbating noninfectious inflammatory diseases [44]. These results suggest that the immunological properties of native MSCs are highly complex, in particular when considering the heterogeneous stromal cell compartment derived from resident MSCs. The field would clearly benefit from the ability to prospectively isolate and characterize relatively pure native stromal cell subsets. A better understanding of the immunomodulatory potential of native MSCs would be highly helpful to design more relevant assays for the qualification of GMP-grade MSCs.

Another important clinical question is to ensure that no significant adverse effects are caused by infusion of immunosuppressive cultured MSCs. In the context of allogeneic stem cell transplantation, how MSCs might inhibit antimicrobial immune response in profoundly immunosuppressed patients is a matter of concern $[39,45]$. However, human MSCs, unlike mouse MSCs, exhibit potent IDO-dependent antimicrobial properties [46]. In fact, the degree of tryptophan depletion required for suppression of microbial growth is far less stringent than that required for T-cell inhibition. Theoretically, MSCs have also the potential to favor cancer progression since they are recruited to sites of neoplasias, integrate into the tumor-associated stroma, release growth factors, angiogenic molecules and metalloproteinases, and suppress anti-tumor immune response. However, no increase of leukemia relapse has been reported after MSCbased graft-versus-host disease treatment [39], probably in part due to the lack of persistence of these cells in vivo. Further investigations with regard to the potential adverse effects of MSC infusion in the context of coexistence or previous diagnosis of neoplastic diseases should be undertaken.

\section{Immunoregulatory properties of mesenchymal stromal cells: clinical applications}

Analyzing how and to what extent GMP-grade MSCs could inhibit immune responses could have several clinical applications. First, it will allow the selection of the 'best' MSCs - that is, identification of appropriate donors and production processes. As for allogeneic MSCs, validation of the process could involve complex phenotypic and functional assays, including mechanistic analyses, since it is performed before the beginning of clinical trials, and could be used at least in part in building a dossier for regulatory authorities. However, release criteria applicable to each MSC batch should be restrained to short-term, fully quantitative pivotal assays. Of course, aliquots of GMP-grade MSCs may be cryopreserved throughout clinical trials to investigate retrospectively new immune markers. The main goal now is to correlate in vitro immune assay results with clinical efficacy, in order to define true potency assays that are currently lacking. This will require both fully standardized in vitro assays and fully standardized clinical trials. To date, the only parameter significantly correlated to T-cell inhibition is the capacity of MSCs to produce active IDO $[18,33]$ but it remains to be firmly demonstrated in forthcoming clinical trials that in vitro quantification of IFN- $\gamma$-induced IDO activity is a good surrogate biological marker of in vivo clinical potency.

Another important issue is the design of relevant immunomonitoring approaches. Whereas MSCs are essentially rapidly cleared in vivo, they are supposed to initiate immune modifications that will amplify their direct initial activity. Proportion of regulatory T cells, modulation of T-cell polarization balance, and plasma levels of inflammatory cytokines and chemokines could be useful to document inflammation dampening. Quantification of IDO activity in plasma should also be evaluated in this context [47]. As previously described in cancer immunotherapy, collection of biopsies after local MSC administration could be highly informative to better understand both their direct and indirect immune activity $[4,48]$.

Finally, dissecting the molecular mechanisms behind MSC-mediated immune suppression could open innovative therapeutic avenues based on the use of these cellderived bioactive factors as a drug instead of MSC themselves, as recently suggested for TSG-6 [29].

\section{Conclusion}

The design of relevant tools to control production processes and final products and to follow up patients involved in clinical trials is of major importance in any cell therapybased therapeutic approach. The field of MSCs has rapidly evolved from the idea that they could differentiate in vivo into various functional cell types to the notion that they exert their beneficial potential through a poorly defined combination of paracrine trophic and immunosuppressive factors. Considering the complexity of these properties, the production, controls, and clinical use of MSCs must take place in interactive research and clinical networks, allowing the definition of validated standards and an in-depth analysis of mechanisms underlying the positive and negative clinical results in a prospective fully integrated approach.

\section{Abbreviations}

ADSC: adipose-derived MSC; BM-MSC: bone marrow-derived MSC; GMP: good manufacturing practice; HLA: human leukocyte antigen; 
IDO: indoleamine 2,3-dioxygenase; IFN: interferon; IL: interleukin; ISCT: international society for cellular therapy; MSC: mesenchymal stromal cell; NF: nuclear factor; NK: natural killer; PCR: polymerase chain reaction; TNF: tumor necrosis factor; TLR: Toll-like receptor.

\section{Competing interests}

The authors declare that they have no competing interests.

\section{Acknowledgements}

This work was supported by grants from the 7th Framework Program of the European Commission: CASCADE (FP7-HEALTH-233236) and REBORNE (FP7HEALTH-241879), award of the European Regional Development Fund (ERDF) allocated by the European Union and by grants from the European Center for Transplantation Sciences and Immunotherapy (IHU CESTI, ANR-10-IBHU0005) and the Infrastructure Program ECELLFRANCE (ANR-11-INSB-005).

\section{Author details}

${ }^{1}$ SITI Laboratory, Etablissement Français du Sang Bretagne, CHU Rennes, Rennes F-35043, France. ' INSERM U917 - Faculté de médecine, 2 Avenue du Pr Léon Bernard, Rennes 35043, France. ${ }^{3}$ Université Rennes 1, UMR 917, Rennes F-35043, France.

\section{Published: 6 June 2013}

\section{References}

1. Uccelli A, Moretta L, Pistoia V: Mesenchymal stem cells in health and disease. Nat Rev Immunol 2008, 8:726-736.

2. Tan J, Wu W, Xu X, Liao L, Zheng F, Messinger S, Sun X, Chen J, Yang S, Cai J, Gao X, Pileggi A, Ricordi C: Induction therapy with autologous mesenchymal stem cells in living-related kidney transplants: a randomized controlled trial. JAMA 2012, 307:1169-1177.

3. Connick P, Kolappan M, Crawley C, Webber DJ, Patani R, Michell AW, Du MQ, Luan SL, Altmann DR, Thompson AJ, Compston A, Scott MA, Miller DH, Chandran S: Autologous mesenchymal stem cells for the treatment of secondary progressive multiple sclerosis: an open-label phase 2a proofof-concept study. Lancet Neurol 2012, 11:150-156.

4. Ciccocioppo R, Bernardo ME, Sgarella A, Maccario R, Avanzini MA, Ubezio C, Minelli A, Alvisi C, Vanoli A, Calliada F, Dionigi P, Perotti C, Locatelli F, Corazza GR: Autologous bone marrow-derived mesenchymal stromal cells in the treatment of fistulising Crohn's disease. Gut 2011, 60:788-798.

5. Le Blanc K, Frassoni F, Ball L, Locatelli F, Roelofs H, Lewis I, Lanino E, Sundberg B, Bernardo ME, Remberger M, Dini G, Egeler RM, Bacigalupo A, Fibbe W, Ringden O: Mesenchymal stem cells for treatment of steroidresistant, severe, acute graft-versus-host disease: a phase II study. Lancet 2008, 371:1579-1586.

6. Hare JM, Fishman JE, Gerstenblith G, Di Fede Velazquez DL, Zambrano JP, Suncion WY, Tracy M, Ghersin E, Johnston PV, Brinker JA, Breton E, DavisSproul J, Schulman IH, Byrnes J, Mendizabal AM, Lowery MH, Rouy D, Altman P, Wong Po Foo C, Ruiz P, Amador A, Da Silva J, McNiece IK, Heldman AW: Comparison of allogeneic vs autologous bone marrowderived mesenchymal stem cells delivered by transendocardial injection in patients with ischemic cardiomyopathy: the POSEIDON randomized trial. JAMA 2012, 308:2369-2379.

7. Sensebe L, Bourin P, Tarte K: Good manufacturing practices production of mesenchymal stem/stromal cells. Hum Gene Ther 2011, 22:19-26.

8. De Ugarte DA, Alfonso Z, Zuk PA, Elbarbary A, Zhu M, Ashjian P, Benhaim P, Hedrick MH, Fraser JK: Differential expression of stem cell mobilizationassociated molecules on multi-lineage cells from adipose tissue and bone marrow. Immunol Lett 2003, 89:267-270.

9. Pachon-Pena G, Yu G, Tucker A, Wu X, Vendrell J, Bunnell BA, Gimble JM: Stromal stem cells from adipose tissue and bone marrow of agematched female donors display distinct immunophenotypic profiles. J Cell Physiol 2011, 226:843-851.

10. Noel D, Caton D, Roche S, Bony C, Lehmann S, Casteilla L, Jorgensen C, Cousin B: Cell specific differences between human adipose-derived and mesenchymal-stromal cells despite similar differentiation potentials. Exp Cell Res 2008, 314:1575-1584.

11. Krampera M, Galipeau J, Shi Y, Tarte K, Sensebe L: Immunological characterization of multipotent mesenchymal stromal cells. The
International Society for Cellular Therapy (ISCT) working proposal. Cytotherapy 2013. doi:10.1016/j.jcyt.2013.02.010.

12. Ren G, Su J, Zhang L, Zhao X, Ling W, L'Huillie A, Zhang J, Lu Y, Roberts Al, Ji W, Zhang H, Rabson AB, Shi Y: Species variation in the mechanisms of mesenchymal stem cell-mediated immunosuppression. Stem Cells 2009, 27:1954-1962.

13. Le Blanc K, Mougiakakos D: Multipotent mesenchymal stromal cells and the innate immune system. Nat Rev Immunol 2012, 12:383-396.

14. Spaggiari GM, Capobianco A, Abdelrazik H, Becchetti F, Mingari MC, Moretta $L$ : Mesenchymal stem cells inhibit natural killer-cell proliferation, cytotoxicity, and cytokine production: role of indoleamine 2,3dioxygenase and prostaglandin E2. Blood 2008, 111:1327-1333.

15. Prigione I, Benvenuto F, Bocca P, Battistini L, Uccelli A, Pistoia V: Reciprocal interactions between human mesenchymal stem cells and gammadelta T cells or invariant natural killer T cells. Stem Cells 2009, 27:693-702.

16. Nauta AJ, Kruisselbrink AB, Lurvink E, Willemze R, Fibbe WE: Mesenchymal stem cells inhibit generation and function of both CD34+-derived and monocyte-derived dendritic cells. J Immunol 2006, 177:2080-2087.

17. Guilloton F, Caron G, Menard C, Pangault C, Ame-Thomas P, Dulong J, De Vos J, Rossille D, Henry C, Lamy T, Fouquet O, Fest T, Tarte K: Mesenchymal stromal cells orchestrate follicular lymphoma cell niche through the CCL2-dependent recruitment and polarization of monocytes. Blood 2012, 119:2556-2567.

18. Francois M, Romieu-Mourez R, Li M, Galipeau J: Human MSC suppression correlates with cytokine induction of indoleamine 2,3-dioxygenase and bystander M2 macrophage differentiation. Mol Ther 2012, 20:187-195.

19. Kim J, Hematti P: Mesenchymal stem cell-educated macrophages: a novel type of alternatively activated macrophages. Exp Hematol 2009, 37:1445-1453.

20. Krampera M: Mesenchymal stromal cell 'licensing': a multistep process. Leukemia 2011, 25:1408-1414.

21. Benvenuto F, Ferrari S, Gerdoni E, Gualandi F, Frassoni F, Pistoia V, Mancardi G, Uccelli A: Human mesenchymal stem cells promote survival of T cells in a quiescent state. Stem Cells 2007, 25:1753-1760.

22. Cassatella MA, Mosna F, Micheletti A, Lisi V, Tamassia N, Cont C, Calzetti F, Pelletier M, Pizzolo G, Krampera M: Toll-like receptor-3-activated human mesenchymal stromal cells significantly prolong the survival and function of neutrophils. Stem Cells 2011, 29:1001-1011.

23. Maby-El Hajjami H, Ame-Thomas P, Pangault C, Tribut O, DeVos J, Jean R, Bescher N, Monvoisin C, Dulong J, Lamy T, Fest T, Tarte K: Functional alteration of the lymphoma stromal cell niche by the cytokine context: role of indoleamine-2,3 dioxygenase. Cancer Res 2009, 69:3228-3237.

24. Franquesa M, Hoogduijn MJ, Bestard O, Grinyo JM: Immunomodulatory effect of mesenchymal stem cells on B cells. Front Immunol 2012, 3:212.

25. Francois M, Romieu-Mourez R, Stock-Martineau S, Boivin MN, Bramson JL, Galipeau J: Mesenchymal stromal cells cross-present soluble exogenous antigens as part of their antigen-presenting cell properties. Blood 2009, 114:2632-2638.

26. Selmani Z, Naji A, Zidi I, Favier B, Gaiffe E, Obert L, Borg C, Saas P, Tiberghien P, Rouas-Freiss N, Carosella ED, Deschaseaux F: Human leukocyte antigen-G5 secretion by human mesenchymal stem cells is required to suppress $T$ lymphocyte and natural killer function and to induce CD4+CD25highFOXP3+ regulatory T cells. Stem Cells 2008, 26:212-222

27. Choi H, Lee RH, Bazhanov N, Oh JY, Prockop DJ: Anti-inflammatory protein TSG- 6 secreted by activated MSCs attenuates zymosan-induced mouse peritonitis by decreasing TLR2/NF-kappaB signaling in resident macrophages. Blood 2011, 118:330-338.

28. Lee RH, Pulin AA, Seo MJ, Kota DJ, Ylostalo J, Larson BL, Semprun-Prieto L, Delafontaine P, Prockop DJ: Intravenous hMSCs improve myocardial infarction in mice because cells embolized in lung are activated to secrete the anti-inflammatory protein TSG-6. Cell Stem Cell 2009, 5:54-63.

29. Oh JY, Roddy GW, Choi H, Lee RH, Ylostalo JH, Rosa RH Jr, Prockop DJ: Antiinflammatory protein TSG-6 reduces inflammatory damage to the cornea following chemical and mechanical injury. articletProc Natl Acad Sci U S A 2010, 107:16875-16880.

30. Danchuk S, Ylostalo JH, Hossain F, Sorge R, Ramsey A, Bonvillain RW, Lasky JA, Bunnell BA, Welsh DA, Prockop DJ, Sullivan DE: Human multipotent stromal cells attenuate lipopolysaccharide-induced acute lung injury in mice via secretion of tumor necrosis factor-alpha-induced protein 6 . Stem Cell Res Ther 2011, 2:27. 
31. Ren G, Zhang L, Zhao X, Xu G, Zhang Y, Roberts Al, Zhao RC, Shi Y: Mesenchymal stem cell-mediated immunosuppression occurs via concerted action of chemokines and nitric oxide. Cell Stem Cell 2008 2:141-150.

32. Romieu-Mourez R, Francois M, Boivin MN, Bouchentouf M, Spaner DE, Galipeau J: Cytokine modulation of TLR expression and activation in mesenchymal stromal cells leads to a proinflammatory phenotype. $J$ Immunol 2009, 182:7963-7973.

33. Menard C, Pacelli L, Bassi G, Dulong J, Bifari F, Bezier I, Zanoncello J, Ricciardi M, Latour M, Bourin P, Schrezenmeier H, Sensebe L, Tarte K, Krampera M: Clinical-grade mesenchymal stromal cells produced under various GMP processes differ in their immunomodulatory properties: Standardization of immune quality controls. Stem Cells Dev 2013. in press.

34. Zhukareva V, Obrocka M, Houle JD, Fischer I, Neuhuber B: Secretion profile of human bone marrow stromal cells: donor variability and response to inflammatory stimuli. Cytokine 2010, 50:317-321.

35. Sensebe L, Tarte K, Galipeau J, Krampera M, Martin I, Phinney DG, Shi Y: Limited acquisition of chromosomal aberrations in human adult mesenchymal stromal cells. Cell Stem Cell 2012, 10:9-10. author reply $10-11$.

36. Cakouros D, Isenmann S, Cooper L, Zannettino A, Anderson P, Glackin C, Gronthos S: Twist-1 induces Ezh2 recruitment regulating histone methylation along the Ink4A/Arf locus in mesenchymal stem cells. Mol Cell Biol 2012, 32:1433-1441.

37. Bork S, Pfister S, Witt H, Horn P, Korn B, Ho AD, Wagner W: DNA methylation pattern changes upon long-term culture and aging of human mesenchymal stromal cells. Aging Cell 2010, 9:54-63.

38. Coppe JP, Desprez PY, Krtolica A, Campisi J: The senescence-associated secretory phenotype: the dark side of tumor suppression. Annu Rev Pathol 2010, 5:99-118.

39. von Bahr L, Sundberg B, Lonnies L, Sander B, Karbach $H$, Hagglund $H$, Ljungman P, Gustafsson B, Karlsson H, Le Blanc K, Ringden O: Long-term complications, immunologic effects, and role of passage for outcome in mesenchymal stromal cell therapy. Biol Blood Marrow Transplant 2012, 18:557-564.

40. Galipeau J: The mesenchymal stromal cells dilemma - does a negative phase III trial of random donor mesenchymal stromal cells in steroidresistant graft-versus-host disease represent a death knell or a bump in the road? Cytotherapy 2013, 15:2-8.

41. Francois M, Copland IB, Yuan S, Romieu-Mourez R, Waller EK, Galipeau J: Cryopreserved mesenchymal stromal cells display impaired immunosuppressive properties as a result of heat-shock response and impaired interferon-gamma licensing. Cytotherapy 2012, 14:147-152.

42. Benezech C, Mader E, Desanti G, Khan M, Nakamura K, White A, Ware CF, Anderson G, Caamano JH: Lymphotoxin-beta receptor signaling through NF-kappaB2-RelB pathway reprograms adipocyte precursors as lymph node stromal cells. Immunity 2012, 37:721-734.

43. Fujisaki J, Wu J, Carlson AL, Silberstein L, Putheti P, Larocca R, Gao W, Saito TI, Lo Celso C, Tsuyuzaki H, Sato T, Cote D, Sykes M, Strom TB, Scadden DT, Lin CP: In vivo imaging of Treg cells providing immune privilege to the haematopoietic stem-cell niche. Nature 2011, 474:216-219.

44. Shi C, Jia T, Mendez-Ferrer S, Hohl TM, Serbina NV, Lipuma L, Leiner I, Li MO, Frenette PS, Pamer EG: Bone marrow mesenchymal stem and progenitor cells induce monocyte emigration in response to circulating toll-like receptor ligands. Immunity 2011, 34:590-601.

45. Forslow U, Blennow O, LeBlanc K, Ringden O, Gustafsson B, Mattsson J, Remberger M: Treatment with mesenchymal stromal cells is a risk factor for pneumonia-related death after allogeneic hematopoietic stem cell transplantation. Eur J Haematol 2012, 89:220-227.

46. Meisel R, Brockers S, Heseler K, Degistirici O, Bulle H, Woite C, Stuhlsatz S, Schwippert W, Jager M, Sorg R, Henschler R, Seissler J, Dilloo D, Daubener $W$ : Human but not murine multipotent mesenchymal stromal cells exhibit broad-spectrum antimicrobial effector function mediated by indoleamine 2,3-dioxygenase. Leukemia 2011, 25:648-654.

47. Dander $E$, Lucchini $G$, Vinci $P$, Introna M, Masciocchi F, Perseghin P, Balduzzi A, Bonanomi S, Longoni D, Gaipa G, Belotti D, Parma M, Algarotti A, Capelli C, Golay J, Rovelli A, Rambaldi A, Biondi A, Biagi E, D'Amico G: Mesenchymal stromal cells for the treatment of graft-versus-host disease: understanding the in vivo biological effect through patient immune monitoring. Leukemia 2012, 26:1681-1684.

48. Ciccocioppo R, Russo ML, Bernardo ME, Biagi F, Catenacci L, Avanzini MA, Alvisi C, Vanoli A, Manca R, Luinetti O, Locatelli F, Corazza GR: Mesenchymal stromal cell infusions as rescue therapy for corticosteroid-refractory adult autoimmune enteropathy. Mayo Clin Proc 2012, 87:909-914.

doi:10.1186/scrt214

Cite this article as: Ménard and Tarte: Immunoregulatory properties of clinical grade mesenchymal stromal cells: evidence, uncertainties, and clinical application. Stem Cell Research \& Therapy 2013 4:64. 